\title{
ABERTURA À MUDANÇA E ENGAJAMENTO NO TRABALHO COMO ANTECEDENTES DA SATISFAÇÃO DO SERVIDOR PÚBLICO
}

\section{OPENING CHANGE AND WORK ENGAGEMENT AS A BACKGROUND TO PUBLIC SERVER SATISFACTION}

FATIMA CRISTINA ARAUJO MAVIGNO

Fucape Business School

Mestre em Administração

Orcid: https://orcid.org/0000-0003-4268-3543

E-mail: fatima@mavigno.com

Av. Fernando Ferrari, 1358, Boa Vista - Vitória/ES, CEP: 29.075-505

\section{EMERSON WAGNER MAINARDES \\ Fucape Business School \\ Doutor em Administração}

Orcid: https://orcid.org/0000-0003-2525-275X

E-mail: emerson@fucape.br

Submissão: 23/03/2020. Revisão: 24/03/2021. Aceite: 27/04/2021. Publicação: 06/09/2021. DOI: http://dx.doi.org/10.22277/rgo.v14i3.5325

\section{RESUMO}

Este estudo teve com o objetivo compreender a influência do traço de personalidade de abertura à mudança e do engajamento no trabalho na satisfação na carreira e na satisfação com a vida do servidor público. Uma survey respondida por servidores públicos, e dados analisados por meio da Modelagem de Equações Estruturais, apresentou resultados significativos entre os construtos: abertura à mudança e satisfação na carreira; engajamento no trabalho e satisfação na carreira; e engajamento no trabalho e satisfação com a vida. A relação entre os construtos abertura à mudança e satisfação com a vida não foi significativa. Conclui-se que a percepção que o servidor público tem de satisfação na carreira tende a ser influenciada tanto pela sua abertura à mudança quanto pelo seu engajamento no trabalho. No caso de satisfação com a vida, há evidência de que esta tende a ser influenciada apenas pelo engajamento do servidor no trabalho que realiza.

Palavras-chave: Servidor público. Engajamento. Abertura à mudança. Satisfação.

Este é um artigo publicado em acesso aberto (Open Access) sob a licença Creative Commons Attribution, que permite uso, distribuição e reprodução em qualquer meio, sem restrições desde que o trabalho original seja corretamente citado. 


\begin{abstract}
This study aimed to understand the influence of the personality trait open to change and work engagement on career satisfaction and life satisfaction of the civil servant. A survey answered by public servants, and data analyzed through Structural Equation Modeling, showed significant results among the constructs: openness to change and career satisfaction; job engagement and career satisfaction; and job engagement and life satisfaction. The relationship between the constructs openness to change and satisfaction with life was not significant. In conclusion, the public servant's perception of career satisfaction tends to be influenced by both their openness to change and their engagement at work. In the case of satisfaction with life, there is evidence that life tends to be influenced only by the employee's engagement in the work he performs.
\end{abstract}

Keywords: Public servant. Engagement. Openness to change. Satisfaction.

\title{
1 INTRODUÇÃO
}

O processo de modernização do serviço público, iniciado na década de 80 , tem engendrado novos modelos e modismos gerenciais, com vistas ao aprimoramento da estrutura governamental, tendo como foco a eficiência e a eficácia no atendimento das demandas da sociedade (HOOD, 1995; SIQUEIRA; MENDES, 2014). No Brasil, as reformas estatais realizadas basearam-se, entre outros aspectos, nos princípios gerencialistas do New Public Management (NPM) (FONSECA et al., 2013), cujas doutrinas amparavam-se nos debates sobre como a administração pública deveria ser conduzida por critérios profissionais e não por regras ou padrões pré-estabelecidos (HOOD, 1995; ABRUCIO, 2007; LEÓN, 2017).

Segundo Secchi (2009), os novos modelos organizacionais não representam modelos de ruptura, mas um encadeamento de mudanças nas práticas e valores organizacionais. Para Siqueira e Mendes (2014), a modernização do Estado não deve se restringir à mera transferência de tecnologias de gestão do setor privado, mas precisa abranger também a gestão de pessoas, avaliando o impacto que as mudanças, oriundas da reforma gerencial, provocam na subjetividade dos servidores públicos e nas relações de trabalho das instituições públicas. Entretanto, a diretriz gerencialista para resultados tem dado mais ênfase às tarefas e menos às pessoas, desmotivando assim o servidor público que se percebe pressionado pelas ocupações laborais, sem espaços para exercer o diálogo e a criatividade (SIQUEIRA; MENDES, 2014).

Para Souza e Moulin (2014), uma vez que o serviço público é pautado pela ética do bem comum, e que esse valor social repercute na autoestima do servidor, é relevante a compreensão da forma como esse servidor público dá significado ao seu trabalho e se faz sujeito da ação. Os autores afirmam ainda que o serviço público é um trabalho rico em interações humanas e que os servidores públicos, dependendo do tipo de atividade que executam e das mudanças institucionais que vivenciam, são constantemente desafiados em suas habilidades intersubjetivas (o pensar, o agir e os afetos).

Considerando a importância de uma gestão estratégica de pessoas no âmbito da administração pública, este estudo verificou se os construtos de abertura à mudança e engajamento no trabalho têm influência nos construtos satisfação na carreira e satisfação com a vida do servidor público. Na literatura foi identificada uma lacuna no que diz respeito a associação entre tais construtos, sendo estes pouco explorados no contexto do funcionalismo público, que normalmente se comporta de modo diferente do empregado do setor privado 
(BUELENS; VAN DEN BROECK, 2007; BRITO; OLIVEIRA, 2016; TINTI et al., 2017).

O foco no servidor público se justifica pela necessidade de conhecer e entender o quão receptivo às mudanças organizacionais e engajado no trabalho é este servidor que está inserido atualmente em um contexto de novas perspectivas de modernização gerencial, preparando o gestor para melhor condução destas.

Em caráter acadêmico, a contribuição teórica dessa pesquisa estabelece-se por conectar construtos como o traço de personalidade de abertura à mudança e o engajamento no trabalho com as variáveis dependentes satisfação na carreira e na satisfação com a vida, relações pouco exploradas em estudos anteriores. Adicionalmente, o contexto no qual a pesquisa foi aplicada, o funcionalismo público, ambiente pouco investigado em estudos sobre comportamento organizacional (PINHO; OLIVEIRA; SILVA, 2020).

Como contribuição gerencial, a análise dos impactos que o traço de personalidade de abertura à mudança e o engajamento no trabalho provocam na satisfação na carreira e na satisfação com a vida do servidor público configura a possibilidade de uma atuação mais estratégica no gerenciamento e engajamento dos servidores públicos, viabilizando resultados mais relevantes à sociedade, representada pelos usuários dos serviços oferecidos, uma vez que a melhoraria na eficácia da gestão de pessoas implicaria na entrega de serviços públicos de alta qualidade, elevando assim o nível no atendimento ao cidadão (MARQUES; BORGES; REIS, 2016).

\section{REFERENCIAL TEÓRICO}

\subsection{O SETOR PÚBLICO E O SERVIDOR PÚBLICO}

O setor público e o setor privado diferem por diversos fatores, dentre eles pelas características da carreira e da qualificação dos servidores públicos (MARCONI, 2014). Em se tratando de setor público, as principais restrições na sua administração são impostas pelo sistema político e não pelo sistema econômico ou pelas forças de mercado. Com isso, os gestores públicos precisam equilibrar e harmonizar objetivos conflitantes. E essa ambiguidade política fornece uma distinção nítida entre a gestão estratégica em organizações públicas e organizações privadas. A consequência para os gestores públicos é que as metas de desempenho são pouco claras e as técnicas de gerenciamento do setor privado muitas vezes se configuram inadequadas ao setor público (BOYNE, 2002).

Para León (2017), a influência que os políticos têm na alocação de pessoal é uma característica relevante, pois eles podem inclusive interferir no processo de recrutamento e seleção de pessoal. Tendo em vista essas questões, é importante que se compreenda o significado de serviço público e a atribuição do servidor público. O termo "serviço público" é frequentemente usado como sinônimo de serviço governamental abrangendo todos aqueles que trabalham no setor público. Porém, o serviço público significa muito mais do que o locus de emprego, ele é um conceito, uma atitude e um senso de dever (PERRY; WISE, 1990). E o que pode motivar um indivíduo a desempenhar um serviço público é a ideia de agir em domínio público com o propósito de fazer o bem aos outros e a sociedade (PERRY; HONDEGHEM; WISE; 2010).

\subsection{SATISFAÇÃO NA CARREIRA E SATISFAÇÃO COM A VIDA}

Segundo Abraham (2012), a satisfação na carreira indica o parâmetro de realização dos servidores com o seu trabalho. E, quanto mais o ambiente de trabalho do servidor satisfaz seus 
valores, conveniências ou individualidades, maior o nível de satisfação na carreira. Para Marqueze e Moreno (2005), o estudo da satisfação na carreira deve ser debatido tanto pelas áreas sociais quanto pela área da saúde, pois essas duas áreas consideram que o componente afetivo emocional e o componente cognitivo devem fazer parte da análise da satisfação. A maioria das pessoas passa boa parte do seu dia no trabalho. E é o trabalho que lhes garante a manutenção econômica de suas necessidades básicas bem como lhe proporciona um censo de identidade e utilidade social (ROELEN et al., 2008).

Os servidores públicos são diferentes de suas contrapartes do setor privado em termos de valores relacionados ao trabalho, preferências de recompensa, necessidades e tipos de personalidade, pois têm um interesse maior em objetivos altruístas ou ideológicos (WITTMER, 1991; CREWSON, 1997; KLEIN; MASCARENHAS, 2016). Sendo assim, segundo Klein e Mascarenhas (2016), é importante que a gestão de pessoas na área pública aproprie-se de fatores motivacionais extrínsecos e intrínsecos na promoção da satisfação na carreira do servidor público.

Marques, Borges e Reis (2016), destacam que a implantação de um sistema de avaliação individual de desempenho tem uma importante influência para a promoção da satisfação na carreira, pois possibilita que os servidores públicos construam uma percepção positiva das mudanças e cooperem com estas no âmbito do trabalho. Segundo Ribeiro e Oliveira (2016), a administração pública pode potencializar, por meio de reconhecimento e melhores condições de trabalho, a motivação intrínseca dos seus servidores e com isso alcançar os resultados almejados pelos seus principais clientes, os cidadãos.

Em relação à satisfação com a vida, Siqueira e Padovam (2008), a apresentam como uma avaliação pessoal que o indivíduo realiza, a partir da percepção que tem sobre o quão distante ou próximo ele está de suas aspirações. Nesse sentido, a satisfação com a vida pode ser apresentada como um estado psicológico mais ligado ao bem-estar do que a avaliações objetivas da qualidade de vida pessoal. Ou seja, um indivíduo que tenha elevada qualidade de vida poderia relatar insatisfações a partir do julgamento que faz sobre suas próprias conquistas e realizações (SIQUEIRA; PADOVAM, 2008).

Bowling, Eschleman e Wang (2010), encontraram em suas pesquisas relações positivas entre satisfação no trabalho e satisfação com a vida, felicidade, afeto positivo e inexistência de afeto negativo. Para Hall e Richter (1988), as organizações precisam ajudar os trabalhadores a definirem as fronteiras entre a casa e o trabalho e também integrar a família de forma consciente na carreira e no gerenciamento de recursos humanos. Segundo Buelens e Van den Broeck (2007), a maioria dos servidores públicos faz constantemente escolhas entre trabalho e família. Alguns servidores optam por uma vida mais equilibrada, com menos conflitos entre trabalho e família, enquanto outros demonstram um grau de comprometimento com o trabalho e um comportamento de cidadania organizacional bem acentuados, dando mais tempo de si e esforço pessoal.

\subsection{ABERTURA À MUDANÇA}

Percebe-se que a implantação de novos modelos gerenciais no âmbito do serviço público, com vistas à excelência no desempenho organizacional, implicou em mudanças expressivas na vida profissional e pessoal dos servidores públicos (MATTOS; SCHLINDWEIN, 2015). Para Marques, Borges e Reis (2016), as reações dos servidores públicos diante de uma mudança organizacional diferem conforme a avaliação que eles realizam de distintos aspectos da mudança. Se o servidor tem a percepção de que tanto a organização quanto seus gestores não são dignos de resguardar, assegurar e honrar seus interesses, este servidor não apoiará o 
Abertura à mudança e engajamento no trabalho como antecedentes da satisfação do servidor público

processo de mudança, e esse aspecto repercutirá na sua satisfação no trabalho (BOEHM; LYUBOMIRSKY, 2008).

Segundo o estudo de Vasconcellos e Hutz (2008), indivíduos com o traço de personalidade de abertura à mudança estão mais propensos a vivenciar as mudanças de forma positiva, abertos a novas experiências. $\mathrm{O}$ traço de personalidade de abertura à mudança faz referência a comportamentos exploratórios, bem como a abertura a novas experiências. Descreve indivíduos imaginativos e criativos, que se envolvem intensamente com situações que promovam mudanças ou que impliquem novidades (VASCONCELLOS; HUTZ, 2008).

Para Marques, Borges e Reis (2016), os servidores que enfrentam as mudanças de forma positiva, que aceitam o novo sem resistir, mas se adequando a ele, apresentam níveis de satisfação na carreira mais elevados. Assumindo que os estudos anteriormente citados conectam o traço de abertura à mudança com a propensão do indivíduo em encarar mudanças, seja no ambiente ou em processos, com menos resistência, sugere-se que o traço de personalidade de abertura à mudança apresente um impacto positivo à satisfação na carreira do servidor público. Constrói-se, então, a primeira hipótese desse estudo:

H1: O traço de personalidade abertura à mudança influencia positivamente a satisfação na carreira.

De maneira contrária, Judge, Heller e Mount (2002), apontam que o traço de personalidade abertura à mudança tem uma fraca relação com a satisfação no trabalho, em contrapartida, uma forte relação com a satisfação com a vida. O termo satisfação com a vida é descrito como uma avaliação cognitiva positiva da vida pessoal em sua totalidade (GALINHA; RIBEIRO, 2005). Para Pavot e Diener (2008), o julgamento da satisfação com a vida é muito amplo e mudanças momentâneas no humor ou no contexto imediato podem ocasionalmente influenciar os julgamentos de satisfação com a vida. Segundo DiFabio (2017), eventos importantes da vida, tais como mudanças no ambiente de trabalho, podem impactar a percepção individual de satisfação com a vida.

Tendo em vista que uma pessoa feliz seria aberta a novas experiências e capaz cognitivamente de ver o mundo de forma positiva ou neutra (WOYCIEKOSKI; STENERT; HUTZ, 2012), depreende-se que o traço de personalidade de abertura à mudança apresenta um impacto positivo à satisfação com a vida do servidor público. Considerando ainda, que o servidor público tem uma autossatisfação de servir os cidadãos e beneficiar a sociedade ao realizar um serviço público significativo (VIGODA-GADOT; ELDOR; SCHOHAT, 2013), bem como os aspectos que envolvem a abertura ao novo, a segunda hipótese desse estudo é:

$\mathrm{H} 2$ : $\mathrm{O}$ traço de personalidade abertura à mudança influencia positivamente a satisfação com a vida.

\subsection{ENGAJAMENTO NO TRABALHO}

O engajamento no trabalho é um estado de espírito positivo, satisfatório e conectado à atividade desempenhada. É um estado benéfico tanto para a organização quanto para o servidor, pois servidores engajados têm um bom desempenho e estão dispostos a ir além (BAKKER; DEMEROUTI; LIEKE, 2012; WOOD et al., 2020). Para Kahn (1990), as pessoas ocupam diversos papeis no trabalho e esses papeis podem ter graus variados de envolvimento físico, emocional e cognitivo. Quem está pessoalmente engajado mantêm-se dentro de um papel, sem sacrificar um pelo outro (SOUZA; MOULIN, 2014).

Vigoda-Gadot, Eldor e Schohat (2013) afirmam que há características únicas na relação servidor público e organização pública, que decorrem dos diferentes objetivos e da atividade 
singular de um setor no qual seus servidores são motivados por um senso de missão e preferem recompensas intrínsecas, em vez de recompensas extrínsecas. Em consonância com esse pensamento, Buelens e Van den Broeck (2007) afirmam que os servidores públicos são motivados por um forte desejo de servir à comunidade e de promover o interesse público, que não é encontrado entre os seus homólogos do setor privado.

Partindo do pressuposto de que os servidores públicos engajados são indivíduos fisicamente, cognitivamente e emocionalmente interligados com seus papéis de trabalho (CALDAS et al., 2013), apresentam altos níveis de energia, são entusiasmados e ficam totalmente imersos em seu trabalho diário (ELDOR, 2018), sugere-se que o engajamento no trabalho impacta positivamente a satisfação na carreira do servidor público. Propõe-se assim a terceira hipótese:

H3 - O engajamento no trabalho influencia positivamente a satisfação na carreira.

Para Vigoda-Gadot, Eldor e Schohat (2013), o engajamento do servidor público está positivamente relacionado tanto ao desempenho no trabalho quanto aos bons comportamentos de cidadania e a autossatisfação de servir a sociedade. Segundo Buelens e Van den Broeck (2007), os servidores públicos são menos motivados pelo desafio do dinheiro e do trabalho e menos comprometidos com longas jornadas de trabalho, se comparados ao setor privado, por almejarem levar uma vida equilibrada. Os servidores públicos fazem escolhas positivas, tendo como objetivo o respeito por seus próprios ritmos de trabalho, suas vidas pessoais, sua qualidade de vida e suas prioridades familiares.

Considerando o estudo de Gouveia et al. (2005), que afirmam que os indivíduos avaliam e significam de forma diferente domínios específicos de suas vidas, a partir de seus próprios interesses e valores, bem como o estudo de Joo e Lee (2017), no qual verificaram que os funcionários altamente engajados terão maior probabilidade de perceber um nível mais alto de felicidade. $O$ pressuposto de que o indivíduo ao apresentar certo nível de engajamento, esteja confortável e convencido de que as mudanças devem ser incorporadas em sua rotina de trabalho, fará com que ele perceba uma condição de maior satisfação com a vida. Desta maneira a quarta hipótese é apresenta a seguir:

H4 - O engajamento no trabalho influencia positivamente a satisfação com a vida.

\section{METODOLOGIA}

Foi realizada uma pesquisa de natureza quantitativa, do tipo survey, com corte transversal. O campo de estudo foram instituições públicas em todos os níveis e esferas, sem distinção, e o público-alvo foram os servidores públicos federais, estaduais e municipais. A amostragem foi não-probabilística por acessibilidade e a amostra foi composta por 645 respondentes. A coleta de dados foi realizada por meio da aplicação de um questionário eletrônico, autoadministrado, aplicado online, e estruturado com 42 questões, contendo construtos já validados pela literatura. O questionário iniciava com uma questão de controle populacional, cujo objetivo era identificar se o respondente era ou não servidor público. Essa questão foi utilizada como critério de exclusão da amostra (quem respondeu não teve suas respostas excluídas).

Na sequência foram abordadas, como sentenças afirmativas, as questões relativas aos construtos da pesquisa, as quais utilizaram o modelo de resposta baseado na escala de Likert, com valores de 1 a 7, conforme o tipo de grau de concordância ou discordância: 1-Discordo plenamente / 2-Discordo / 3-Discordo um pouco / 4-Não concordo nem discordo / 5-Concordo um pouco / 6-Concordo / 7-Concordo totalmente. Os quatro construtos da pesquisa foram medidos nas questões 2 a 29. O primeiro construto foi o construto satisfação na carreira. 
Abertura à mudança e engajamento no trabalho como antecedentes da satisfação do servidor público

Baseado na escala elaborada por Hofmans, Dries e Pepermans (2008), essa parte do questionário é composta pelas questões 2 a 6 . O segundo construto (questões 7 a 11) abordou a satisfação com a vida (DIENER et al., 1985). As questões de 12 a 20 abordaram o terceiro construto, engajamento no trabalho (SCHAUFELI; BAKKER; SALANOVA, 2006). O último construto abordado foi abertura à mudança (ANDRADE, 2008), presente nas questões de 21 a 29. O questionário foi finalizado com um levantamento de aspectos demográficos dos respondentes, distribuídos nas questões 30 a 42.

Foi realizado um pré-teste semântico com 20 respondentes servidores públicos para validação das questões. Após o pré-teste, o questionário foi disponibilizado em meio eletrônico (e-mail e WhatsApp) aos servidores públicos cadastrados no banco de dados da Escola de Contas Públicas do Tribunal de Contas do Estado do Espírito Santo, contendo o link para o formulário desenvolvido na ferramenta Google Docs.

Do total de 645 respostas, 50,9\% são do gênero feminino. Quanto à faixa etária, a grande maioria $(88,2 \%)$ está no intervalo de 26 a 55 anos. Em termos de nível de escolaridade, destaca-se o nível de pós-graduação $(57,2 \%)$, seguido pelo ensino superior (24,3\%). No item renda familiar, verifica-se que 61,2\% recebem acima de 5 salários mínimos. Em relação ao estado civil atual, grande parte dos respondentes são casados ou vivem em união estável $(68,5 \%)$ e possuem até 2 filhos (54,4\%). A distribuição geográfica dos respondentes foi a seguinte: região Sudeste $(65,1 \%)$, região Nordeste $(14,3 \%)$, região Sul $(9,8 \%)$, região CentroOeste $(7,3 \%)$ e região Norte $(3,6 \%)$.

$\mathrm{Na}$ análise das questões relativas ao serviço público no qual trabalham, a grande maioria dos respondentes são servidores públicos efetivos, ou seja, estão trabalhando na área pública por terem sido aprovados em concursos públicos (82\%). A amostra se divide basicamente entre servidores públicos estaduais $(42,6 \%)$ e servidores públicos municipais $(45,3 \%)$, que atuam principalmente no poder executivo $(53,2 \%)$, não possuem cargo de chefia $(62,9 \%)$ e trabalham em jornadas diárias de $6 \mathrm{~h}$ (32,9\%) ou 8h (50,7\%). Em relação ao tempo de carreira, verifica-se que os respondentes são servidores que atuam há mais de 6 anos no serviço público (78,5\%).

$\mathrm{Na}$ análise dos dados, foi utilizada a modelagem de equações estruturais por meio dos mínimos quadrados parciais (Partial Least Squares Structural Equation Modeling - PLS-SEM), visto que esta permite o teste de múltiplas relações simultaneamente, contemplando construtos endógenos (satisfação na carreira e satisfação com a vida) e exógenos (abertura à mudança e engajamento no trabalho). O processo de análise foi dividido em duas etapas, na primeira foi realizada a avaliação do modelo de mensuração, tendo sido realizada a averiguação da validade convergente, a consistência interna e a validade discriminante do modelo em estudo. A segunda parte da análise considerou a avaliação do modelo estrutural (ou modelo de caminhos), onde foi realizada a avaliação do coeficiente de determinação de Pearson (R2) e a interpretação dos coeficientes de caminho seguindo os critérios apontados no trabalho de Ringle, Silva e Bido (2014).

\section{ANÁLISE DOS DADOS}

Inicialmente foi realizada a análise fatorial confirmatória (AFC). Conforme Souza, Alexandre e Guirardello (2017), o ideal é que as cargas fatoriais apresentem valores superiores a 0,60. Na Tabela 1, verifica-se que as cargas fatoriais apuradas registraram valores adequados, acima de 0,70 . Dando continuidade à validação do modelo de mensuração, foram analisados seus parâmetros psicométricos: validade convergente, consistência interna e 
validade discriminante.

Tabela 1 - Matriz de Cargas Fatoriais

\begin{tabular}{|c|c|c|c|c|c|c|}
\hline Construtos & & Variáveis & AM & ET & SC & SV \\
\hline \multirow{7}{*}{$\begin{array}{c}\text { Abertura à } \\
\text { mudança } \\
\text { (ANDRADE, 2008) }\end{array}$} & AM1 & Eu sou original, tenho sempre novas ideias. & 0,847 & & & \\
\hline & AM2 & Eu sou inventivo(a), criativo(a). & 0,863 & & & \\
\hline & AM3 & $\begin{array}{l}\text { Eu valorizo o artístico, ou seja, dou atenção a } \\
\text { estética das coisas. }\end{array}$ & 0,729 & & & \\
\hline & AM4 & $\begin{array}{l}\text { Eu sou curioso(a) sobre muitas coisas } \\
\text { diferentes. }\end{array}$ & 0,728 & & & \\
\hline & AM5 & Eu tenho uma imaginação fértil. & 0,689 & & & \\
\hline & AM6 & $\begin{array}{l}\text { Eu sou engenhoso(a), alguém que gosta de } \\
\text { analisar profundamente as coisas. }\end{array}$ & 0,753 & & & \\
\hline & AM7 & Eu gosto de refletir, brincar com as ideias. & 0,794 & & & \\
\hline \multirow{9}{*}{$\begin{array}{l}\text { Engajamento no } \\
\text { trabalho } \\
\text { (SCHAUFELI; } \\
\text { BAKKER; } \\
\text { SALANOVA, 2006) }\end{array}$} & ET1 & $\begin{array}{l}\text { No meu trabalho, eu me sinto cheio(a) de } \\
\text { energia. }\end{array}$ & & 0,918 & & \\
\hline & ET2 & $\begin{array}{l}\text { Eu estou entusiasmado(a) com o meu } \\
\text { trabalho. }\end{array}$ & & 0,934 & & \\
\hline & ET3 & $\begin{array}{l}\text { No meu trabalho, eu me sinto forte e com } \\
\text { vigor. }\end{array}$ & & 0,927 & & \\
\hline & ET4 & $\begin{array}{l}\text { Eu fico contente quando estou trabalhando } \\
\text { intensamente. }\end{array}$ & & 0,769 & & \\
\hline & ET5 & O meu trabalho me inspira. & & 0,919 & & \\
\hline & ET6 & Eu me sinto "mergulhado(a)" no trabalho. & & 0,803 & & \\
\hline & ET7 & $\begin{array}{l}\text { Quando eu acordo pela manhã, sinto-me bem } \\
\text { por ir trabalhar. }\end{array}$ & & 0,870 & & \\
\hline & ET8 & Eu tenho orgulho do que faço. & & 0,783 & & \\
\hline & ET9 & $\begin{array}{l}\text { Eu esqueço de tudo quando estou } \\
\text { trabalhando. }\end{array}$ & & 0,671 & & \\
\hline \multirow{5}{*}{$\begin{array}{c}\text { Satisfação na } \\
\text { carreira } \\
\text { (HOFMANS; DRIES; } \\
\text { PEPERMANS, } \\
\text { 2008) }\end{array}$} & SC1 & $\begin{array}{l}\text { Estou satisfeito com o sucesso que consegui } \\
\text { em minha carreira. }\end{array}$ & & & 0,889 & \\
\hline & SC2 & $\begin{array}{l}\text { Estou satisfeito com o progresso que fiz para } \\
\text { atingir meus obietivos gerais de carreira. }\end{array}$ & & & 0,910 & \\
\hline & SC3 & $\begin{array}{l}\text { Estou satisfeito com os progressos que fiz } \\
\text { para atingir meus obietivos financeiros. }\end{array}$ & & & 0,795 & \\
\hline & SC4 & $\begin{array}{l}\text { Estou satisfeito com o progresso que fiz para } \\
\text { alcancar meus obietivos de conhecimento. }\end{array}$ & & & 0,792 & \\
\hline & SC5 & $\begin{array}{l}\text { Estou satisfeito com o progresso que fiz para } \\
\text { atingir meus obietivos para o }\end{array}$ & & & 0,766 & \\
\hline \multirow{5}{*}{$\begin{array}{c}\text { Satisfação com a } \\
\text { vida } \\
\text { (DIENER et al., } \\
\text { 1985) }\end{array}$} & SV1 & $\begin{array}{l}\text { Em muitos aspectos a minha vida está } \\
\text { próxima do meu ideal. }\end{array}$ & & & & 0,874 \\
\hline & SV2 & As condições da minha vida são excelentes. & & & & 0,893 \\
\hline & SV3 & Estou satisfeito com a minha vida. & & & & 0,907 \\
\hline & SV4 & $\begin{array}{l}\text { Dentro do possível, tenho conseguido as } \\
\text { coisas importantes que eu quero na vida. }\end{array}$ & & & & 0,896 \\
\hline & SV5 & $\begin{array}{l}\text { Se eu pudesse viver minha vida novamente, } \\
\text { eu mudaria quase nada. }\end{array}$ & & & & 0,835 \\
\hline
\end{tabular}

Fonte: dados da pesquisa.

A verificação da validade convergente (RINGLE; SILVA; BIDO, 2014) é demonstrada pelo cálculo da variância média extraída (Average Variance Extracted - AVE), cujos valores iguais 
ou superiores a 0,50 representam convergência no modelo (HAIR JUNIOR et al., 2017; SOUZA; ALEXANDRE; GUIRARDELLO, 2017). A variância média extraída (AVE) apurada apresentou valores superiores a 0,50 (Tabela 2), atendendo ao critério de Fornell e Larcker (1981). A consistência interna foi validada por meio da confiabilidade composta com valores acima de 0,70 (Tabela 2). O cálculo da validade discriminante, realizada pelo critério de Fornell e Larcker (1981), indicou que as correlações encontradas entre os construtos apresentaram valores inferiores à raiz quadrada da AVE de cada construto (RINGLE; SILVA; BIDO, 2014; HAIR JUNIOR et al., 2017), conforme demonstrado na Tabela 2, em destaque na diagonal. Com o modelo de mensuração devidamente sustentado, pode-se considerar que as variáveis medidas representam os seus respectivos construtos (HAIR JUNIOR et al., 2017), permitindo o teste do modelo estrutural.

Tabela 2 - Correlações e Estatística dos Construtos

\begin{tabular}{|c|c|c|c|c|c|c|}
\hline \multirow[b]{2}{*}{ Construto } & \multirow{2}{*}{$\begin{array}{c}\text { Variância } \\
\text { Média } \\
\text { Extraída } \\
\text { (AVE) }\end{array}$} & \multirow{2}{*}{$\begin{array}{l}\text { Confiabilidade } \\
\text { Composta (CC) }\end{array}$} & \multicolumn{4}{|c|}{ Validade discriminante } \\
\hline & & & AM & ET & SC & SV \\
\hline Abertura à mudança (AM) & 0,60 & 0,91 & 0,77 & & & \\
\hline Engajamento no trabalho (ET) & 0,72 & 0,96 & 0,40 & 0,85 & & \\
\hline Satisfação na carreira (SC) & 0,69 & 0,92 & 0,34 & 0,72 & 0,83 & \\
\hline Satisfação com a vida (SV) & 0,78 & 0,95 & 0,27 & 0,66 & 0,71 & 0,88 \\
\hline
\end{tabular}

Fonte: dados da pesquisa.

Nota: A diagonal principal da tabela refere-se à raiz quadrada da Variância Média Extraída (AVE).

A hipótese $\mathrm{H} 1$, que afirma que o traço de personalidade abertura à mudança influencia positivamente a satisfação na carreira do servidor público, apresentou um $\Gamma=+0,071$ e um $p$ valor $<0,05$ significativo, sendo assim suportada. Este resultado pode ser interpretado com base na literatura existente sobre o traço de personalidade de abertura a mudança e sobre a satisfação na carreira do servidor público.

Figura 1 - Modelo estrutural proposto

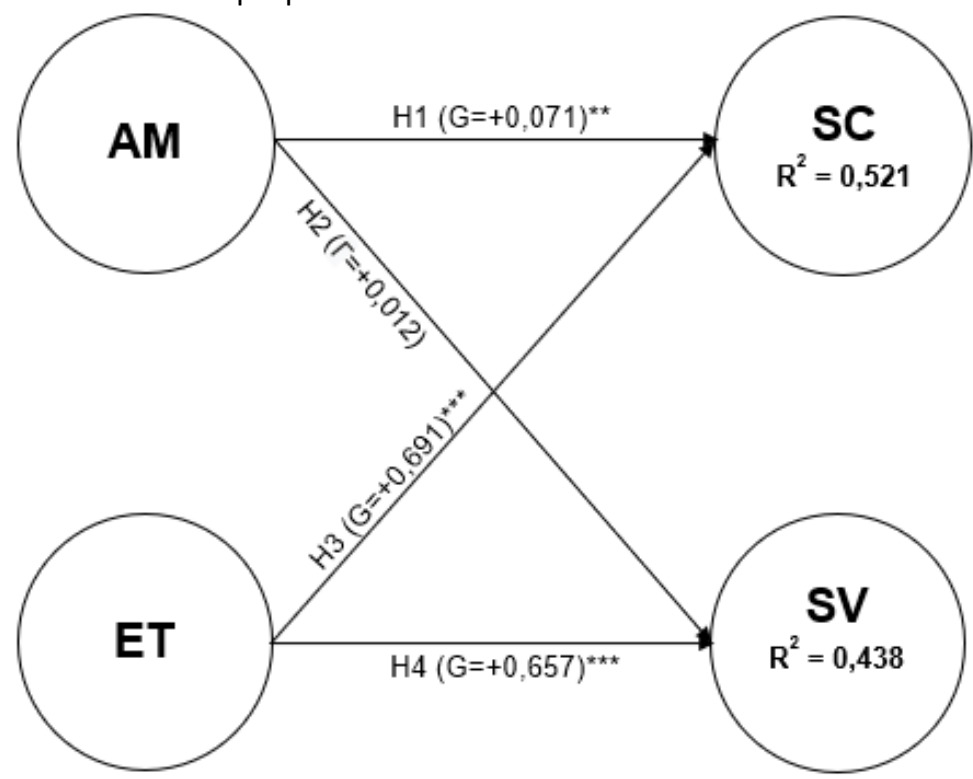

Fonte: Elaborada pelo autor.

Legenda: AM - Abertura à mudança; ET - Engajamento no trabalho; SC - Satisfação na carreira; SV - Satisfação com a vida. $\Gamma$ - coeficiente de caminho. $\mathrm{R}^{2}$ - coeficiente de determinação. **p-valor<0,05; ***p-valor<0,01. 
Segundo Marques, Borges e Reis (2016), os servidores públicos podem entender a mudança como um novo momento a ser vivenciado ou então se sentirem intimidados com ela, e esses sentimentos contraditórios podem impactar a sua vida pessoal e profissional, gerar sentimentos de incerteza e ambiguidade, comprometendo a percepção da satisfação no trabalho. Marques, Borges e Reis (2016), complementam ainda que os servidores que enfrentam as mudanças de forma positiva, apresentam níveis de satisfação na carreira mais elevados.

Tendo em vista o que Boehm e Lyubomirsky (2008), afirmam em seu estudo, que as emoções positivas reverberam no ambiente de trabalho e, por isso, é importante considerar tais emoções no sucesso da carreira, depreende-se do resultado da hipótese 1 que servidores públicos com características do traço de personalidade de abertura à mudança tendem a ser servidores imaginativos, abertos à novas experiências e ecléticos, ou seja, possivelmente são servidores com mais facilidade de encarar de forma positiva as atuais demandas de modernização da administração pública.

Na hipótese $\mathrm{H} 2$, a qual dizia respeito à questão do traço de personalidade abertura à mudança influenciar positivamente a satisfação com a vida do servidor público, o resultado apurado foi $\Gamma=+0,012$ e p-valor de 0,611 não significativo, configurando uma hipótese não suportada. Esse resultado pode justificar-se pela amplitude que o julgamento da satisfação com a vida pode assumir (ALI, 2019), pois sendo a satisfação com a vida uma avaliação cognitiva da vida pessoal como um todo (GALINHA; RIBEIRO, 2005), a vivência de importantes eventos pode impactar a percepção individual de satisfação com a vida (DI FABIO, 2017).

Para Pavot e Diener (2008), mudanças momentâneas no humor ou no contexto imediato tem possibilidades de influenciar as ponderações a respeito de satisfação com a vida. Aliado a isso, tem a questão de que o servidor público se sente satisfeito em sua carreira a partir de fatores extrínsecos, intrínsecos e simbólicos, contidos na própria natureza do seu trabalho (KLEIN; MASCARENHAS, 2016). Considerando que o servidor público faz constantemente escolhas entre trabalho e família, motivados pelo desejo de servir à comunidade e promover o interesse público (BORST; KRUYEN; LAKO, 2019), depreende-se do resultado da hipótese $\mathrm{H} 2$ que essas escolhas não dependem necessariamente do quão aberto a mudanças os servidores públicos estejam, mas de como estes avaliam o impacto dessas mudanças em sua vida.

Em relação à hipótese $\mathrm{H} 3$, que se refere ao engajamento no trabalho influenciar positivamente a satisfação na carreira, os valores aferidos foram o $\Gamma=+0,691$ e o $p$-valor < 0,01 , sendo, pois, suportada. A explicação para esse resultado está presente na literatura, quando Vigoda-Gadot, Eldor e Schohat (2013), afirmam que o engajamento no trabalho tende a ser mais elevado entre servidores públicos do que entre funcionários do setor privado, e que servidores públicos engajados potencialmente são, segundo Caldas et al. (2013), fisicamente, cognitivamente e emocionalmente conectados aos seus papéis de trabalho.

Caldas et al. (2013), afirmam também que servidores públicos engajados têm um desempenho superior aos não engajados. Para Vigoda-Gadot, Eldor e Schohat (2013), o engajamento no trabalho do servidor público está relacionado não só ao desempenho no trabalho, mas também às boas práticas de cidadania e à realização de um serviço público significativo. São diferentes valores internos e fatores intrínsecos que, associados ao senso de "missão" para com a sociedade, intensificam o relacionamento do servidor público com a sua organização.

Considerando que o engajamento no trabalho é um estado de espirito positivo, satisfatório e relacionado à atividade laboral desempenhada (BAKKER; DEMEROUTI; LIEKE, 
2012; WOOD et al., 2020), o resultado da hipótese H3 permite inferir que o servidor público se engaja no seu trabalho quando o faz acreditando que ele contribui para o exercício de sua missão, que é atender os anseios da sociedade no que lhe cabe, e essa motivação intrínseca tende a gerar emoções positivas de satisfação na carreira desse servidor público.

A hipótese $\mathrm{H} 4$, relativa ao engajamento no trabalho influenciar positivamente a satisfação com a vida, também foi suportada, conforme os valores do $\Gamma=+0,657$ e do $p$-valor $<0,01$. Esta percepção também é verificada na literatura. Segundo Vigoda-Gadot, Eldor e Schohat (2013), o engajamento no trabalho do servidor público está positivamente relacionado tanto ao desempenho no trabalho quanto aos bons comportamentos de cidadania e à autossatisfação de servir a sociedade. Para Buelens e Van den Broeck (2007), os servidores públicos, por aspirarem levar uma vida equilibrada, fazem escolhas positivas, que respeitem seus próprios ritmos de trabalho, suas vidas pessoais, sua qualidade de vida e suas prioridades familiares (BORST; KRUYEN; LAKO, 2019).

Complementando essa ideia, Joo e Lee (2017), verificaram que os funcionários altamente engajados têm maior probabilidade de perceber um nível mais alto de felicidade. Como foi dito anteriormente, o servidor público se sente motivado com o cumprimento de sua missão de cidadania, e essa percepção positiva de ser bem-sucedido no que faz e trabalhar com vigor e energia na sua missão pode torna-lo mais feliz.

Finalizando a avaliação dos resultados, verifica-se que o construto engajamento no trabalho tende a anteceder tanto o construto satisfação na carreira quanto o construto satisfação com a vida. No caso do construto abertura à mudança, este tende a anteceder apenas o construto satisfação na carreira. Os valores apurados demonstram que a satisfação na carreira do servidor público é explicada em 52,10\% pela influência exercida pelos construtos que a antecedem, abertura à mudança e engajamento no trabalho. Isso significa que os servidores públicos com traço de personalidade de abertura à mudança são servidores mais receptivos às mudanças que ocorrem no seu ambiente de trabalho, demonstrando atitudes positivas em relação a novas experiências de aprendizado, sem resistir, mas se adequando e trabalhando em prol dos resultados almejados.

Ao mesmo tempo, o engajamento no trabalho faz com que os servidores se sintam mais integrados aos seus papéis de trabalho, acreditando na atividade que exercem, no projeto que participam, pois estes contribuem para a sua missão enquanto servidor público. Sendo assim, a influência dos construtos abertura à mudança e engajamento no trabalho reflete-se positivamente na percepção de satisfação com a carreira do servidor público. No entanto, essa influência explica apenas $52,10 \%$ do construto satisfação na carreira e os $47,90 \%$ restantes são explicados por outros fatores que não foram abrangidos por essa pesquisa.

Já a satisfação com a vida do servidor público é explicada em $43,80 \%$ pela influência do construto engajamento no trabalho. Verifica-se então que a presença do traço de abertura à mudança na personalidade do servidor público não impacta na sua percepção de satisfação com a vida. Esse resultado pode ser explicado pelo fato de que a avaliação de satisfação com a vida é muito ampla e alterações de humor, ou mesmo do contexto do momento em que se vive, pode influenciar os julgamentos nessa seara (ALI, 2019). Porém, no caso do engajamento no trabalho é diferente, pois este construto tende a influenciar positivamente na percepção que o servidor público tem de satisfação com a vida que ele vive.

A explicação pode estar baseada na questão de que o engajamento não se relaciona apenas com o desempenho no trabalho, mas também com os bons comportamentos de cidadania e autossatisfação de servir à sociedade (ELDOR, 2018). E o servidor público, ao se engajar em um trabalho no qual acredita que o seu desempenho faz a diferença na sociedade 
em que vive, que cumpre o seu papel como cidadão, tende a perceber um nível mais alto de felicidade e plenitude em sua vida. É importante destacar que outros fatores que não foram abarcados por essa pesquisa devem explicar os $56,20 \%$ restantes do construto satisfação com a vida do servidor público, complementando o seu entendimento.

Por fim, no modelo estrutural proposto nessa pesquisa, das quatro hipóteses apresentadas apenas uma não foi suportada, que foi a hipótese que relacionou abertura à mudança com satisfação com a vida. As demais hipóteses, que relacionavam tanto a abertura à mudança quanto o engajamento no trabalho à satisfação na carreira e engajamento no trabalho à satisfação com a vida, foram todas suportadas. Tendo em vista que o serviço público é um valor social pautado pela ética do bem comum, que se reflete na autoestima do servidor público, e considerando as hipóteses suportadas, percebe-se que é relevante compreender a forma como o servidor público dá sentido ao seu trabalho e se faz sujeito dessa ação (SOUZA; MOULIN, 2014).

Com base nos resultados aferidos, percebe-se que o servidor público que possui em sua personalidade o traço de abertura à mudança tende a estar mais aberto ao novo e, diante de um contexto de transformação gerencial pela qual passa a administração pública em geral, esse servidor público tem a possibilidade de assimilar com mais leveza as novas experiências, de forma que essas mudanças sejam percebidas positivamente na sua carreira. Análise semelhante pode ser feita em relação ao engajamento no trabalho.

Um servidor público engajado é um servidor que acredita no propósito do seu trabalho e o direciona a um objetivo concreto, é um servidor que busca alcançar os resultados almejados. Esse engajamento no trabalho pode proporcionar ao servidor público a satisfação na carreira que exerce enquanto uma missão, percebendo-se proativo e gerando valor para sociedade, que é o seu principal cliente. Enfatizando ainda papel do engajamento no trabalho, este construto também tende a exercer influência na percepção de satisfação com a vida que o servidor público vive, pois ele pode se sentir realizado quando desempenha uma atividade laboral que faz diferença positiva na sociedade da qual ele e sua família fazem parte como cidadãos.

\section{CONSIDERAÇÕES FINAIS}

O presente estudo teve como objetivo identificar a relação existente entre o construto abertura à mudança e os construtos satisfação na carreira e satisfação com a vida do servidor público, bem como a relação existente entre o construto engajamento no trabalho e os construtos satisfação na carreira e satisfação com a vida do servidor público.

Com base nos resultados obtidos, conclui-se que a percepção de satisfação na carreira do servidor público tem uma relação direta com o juízo positivo que o servidor faz das mudanças que ocorrem no seu ambiente organizacional (abertura à mudança), e também com a conexão que este servidor tem com o papel desempenhado no serviço público (engajamento no trabalho). No caso da percepção de satisfação com a vida, infere-se que o vínculo que o servidor público estabelece com o seu papel de trabalho (engajamento no trabalho) tende a repercutir positivamente na vida desse servidor.

A contribuição teórica dessa pesquisa está na compreensão do quanto o engajamento no trabalho e a abertura à mudança influenciam a satisfação dos servidores públicos, considerando sua carreira e sua vida pessoal. Essa análise pode auxiliar os gestores da área pública a entenderem melhor as reações dos seus subordinados, conduzindo-os de forma mais efetiva no atual contexto de modernização da administração pública, que por meio da implementação de novos modelos gerenciais busca entregar resultados que atendam aos 
anseios da sociedade.

Como limitações desse estudo, dois pontos relacionados a características da amostra devem ser destacados: a concentração de respondentes na região sudeste $(65,1 \%)$, e o baixo número de servidores federais $(11,2 \%)$. Uma outra limitação é o corte transversal da amostra. Uma pesquisa longitudinal permitiria uma análise mais acurada da percepção de satisfação desses servidores durante as diversas fases de um projeto ou de uma gestão. Por último, não foi verificada a frustração do servidor público por não exercer a sua aptidão, o que poderia ter interferência nas variáveis observadas.

Pesquisas futuras, poderiam analisar a percepção de satisfação, tanto na carreira quanto com a vida, que tem o servidor público no contexto nacional e efetuar comparações entre regiões. Outra possibilidade seria a ampliação da investigação a respeito dos traços de personalidade que poderiam impactar tanto a satisfação com a vida quanto a satisfação na carreira, considerando as demais dimensões do modelo dos cinco fatores de personalidade, também conhecido como Big Five.

Sugere-se também, que pesquisas futuras realizem uma comparação entre servidores públicos que se autodeclararam realizados na carreira com servidores não realizados na carreira, bem como entre os servidores públicos das esferas municipal, estadual e federal. Por fim, averiguar se a satisfação na carreira influencia positivamente a percepção que o servidor público tem de satisfação com a vida.

\section{REFERÊNCIAS}

ABRAHAM, S. Job satisfaction as an antecedent to employee engagement. SIES Journal of Management, v. 8, n. 2, p. 27-36, 2012.

ABRUCIO, F. L. Trajetória recente da gestão pública brasileira: um balanço crítico e a renovação da agenda de reformas. Revista de Administração Pública-RAP, v. 41, n. esp., p. 67-86, 2007.

ALI, I. Personality traits, individual innovativeness and satisfaction with life. Journal of Innovation \& Knowledge, v. 4, n. 1, p. 38-46, 2019. DOI: https://doi.org/10.1016/j.jik.2017.11.002.

ANDRADE, J. M. (2008). Evidências de validade do inventário dos cinco grandes fatores de personalidade para o Brasil. 2008. 169 f. Tese (Doutorado em Psiscologia, do Trabalho e das Organizações) - Programa de Pós-Graduação em Psicologia Social, do Trabalho e das Organizações, Universidade de Brasília, Brasília, 2008.

BAKKER, A. B.; DEMEROUTI, E.; LIEKE, L. Work engagement, performance, and active learning: The role of conscientiousness. Journal of Vocational Behavior, v. 80, n. 2, p. 555564, 2012. DOI: https://doi.org/10.1016/j.jvb.2011.08.008.

BOEHM, J. K.; LYUBOMIRSKY, S. Does happiness promote career success? Journal of Career Assessment, v. 16, n. 1, p. 101-116, 2008. DOI: https://doi.org/10.1177/1069072707308140.

BORST, R. T.; KRUYEN, P. M.; LAKO, C. J. Exploring the job demands-resources model of work engagement in government: Bringing in a psychological perspective. Review of Public Personnel Administration, v. 39, n. 3, p. 372-397, 2019. DOI: 
https://doi.org/10.1177/0734371X17729870.

BOWLING, N. A.; ESCHLEMAN, K. J.; WANG, Q. A meta-analytic examination of the relationship between job satisfaction and subjective well-being. Journal of Occupational and Organizational Psychology, v. 83, n. 4, p. 915-934, 2010. DOI: https://doi.org/10.1348/096317909X478557.

BOYNE, G. A. Public and private management: What's the difference? Journal of Management Studies, v. 39, n. 1, p. 97-122, 2002. DOI: https://doi.org/10.1111/14676486.00284 .

BRITO, R. P.; OLIVEIRA, L. B. The relationship between human resource management and organizational performance. Brazilian Business Review, v. 13, n. 3, p. 90-110, 2016. DOI: https://doi.org/10.15728/bbr.2016.13.3.5.

BUELENS, M.; VAN DEN BROECK, $\mathrm{H}$. An analysis of differences in work motivation between public and private sector organizations. Public Administration Review, v. 67. n. 1, p. 65-74, 2007. DOI: https://doi.org/10.1111/j.1540-6210.2006.00697.x.

CALDAS, C. B.; SOMENSARI, P.; COSTA, S. N.; SIQUEIRA, M. M. M.; CLARO, J. A. C.

S. Satisfação e engajamento no trabalho: Docentes temáticos e auxiliares da EAD de universidade privada brasileira. Gerais: Revista Interinstitucional de Psicologia, v. 6, n. 2, p. 225-237, 2013.

CREWSON, P. E. Public-service motivation: Building empirical evidence of incidence and effect. Journal of Public Administration Research and Theory, v. 7, n. 4, p. 499-518, 1997. DOI: https://doi.org/10.1093/oxfordjournals.jpart.a024363.

DIENER, E.; EMMONS, R. A.; LARSEN, R. J.; GRIFFIN, S. The satisfaction with life scale. Journal of Personality Assessment, v. 49, n. 1, p. 71-75, 1985. DOI: https://doi.org/10.1207/s15327752jpa4901_13.

DI FABIO, A. Positive healthy organizations: Promoting well-being, meaningfulness, and sustainability in organizations. Frontiers in Psychology, v. 8, p. 1938, 2017. DOI: https://doi.org/10.3389/fpsyg.2017.01938.

ELDOR, L. Public service sector: The compassionate workplace: The effect of compassion and stress on employee engagement, burnout, and performance. Journal of Public Administration Research and Theory, v. 28, n. 1, p. 86-103, 2018. DOI: https://doi.org/10.1093/jopart/mux028.

FONSECA, D. R.; MENESESP, P. P. M.; SILVA FILHO, A. I.; CAMPOS, N. G. Autonomia para gestão estratégica de pessoas no setor público federal: perspectivas de análise e agenda de pesquisa. Revista de Administração Pública, v. 47, n. 6, p. 1451-1476, 2013.

FORNELL, C.; LARCKER, D. F. Evaluating structural equation models with unobservable variables and measurement error. Journal of Marketing Research, v. 18, n. 1, p. 39-50, 1981. DOI: https://doi.org/10.1177/002224378101800104. 
Abertura à mudança e engajamento no trabalho como antecedentes da satisfação do servidor público

GALINHA, I.; RIBEIRO, J. L. Pais. História e evolução do conceito de bem-estar subjectivo. Psicologia, Saúde \& Doenças, v. 6, n. 2, p. 203-214, 2005.

GOUVEIA, V. V.; BARBOSA, G. A.; ANDRADE, E. O.; CARNEIRO, M. B. Medindo a satisfação com a vida dos médicos no Brasil. Jornal Brasileiro de Psiquiatria, v. 54, n. 4, p. 298-305, 2005.

HALL, D. T.; RICHTER, J. Balancing work life and home life: What can organizations do to help? Academy of Management Perspectives, v. 2, n. 3, p. 213-223, 1988. DOI: https://doi.org/10.5465/ame.1988.4277258.

HAIR JUNIOR, J. F.; HULT, G. M.; RINGLE, C.; SARSTEDT, M. A primer on partial least squares structural equation modeling (PLS-SEM). 2 ed., Los Angeles: Sage, 2017.

HOFMANS, J.; DRIES, N.; PEPERMANS, R. The career satisfaction scale: Response bias among men and women. Journal of Vocational Behavior, v. 73, n. 3, p. 397-403, 2008. DOI: https://doi.org/10.1016/j.jvb.2008.08.001 .

HOOD, C. The "New Public Management" in the 1980s: Variations on a theme. Accounting, Organizations and Society, v. 20, n. 2-3, p. 93-109, 1995. DOI: https://doi.org/10.1016/0361-3682(93)E0001-W.

JOO, B. K.; LEE, I. Workplace happiness: Work engagement, career satisfaction, and subjective well-being. Evidence-based HRM: a Global Forum for Empirical Scholarship, v. 5, n. 2, p. 206-221, 2017. DOI: https://doi.org/10.1108/EBHRM-04-2015-0011.

JUDGE, T. A.; HELLER, D.; MOUNT, M. K. Five-factor model of personality and job satisfaction: a meta-analysis. Journal of Applied Psychology, v. 87, n. 3, p. 530, 2002. DOI: https://doi.org/10.1037/0021-9010.87.3.530.

KAHN, W. A. Psychological conditions of personal engagement and disengagement at work. Academy of Management Journal, v. 33, n. 4, p. 692-724, 1990. DOI: https://doi.org/10.5465/256287.

KLEIN, F. A.; MASCARENHAS, A. O. Motivação, satisfação profissional e evasão no serviço público: $O$ caso da carreira de especialistas em Políticas Públicas e Gestão Governamental. Revista de Administração Pública, v. 50, n. 1, p. 17-39, 2016. DOI: https://doi.org/10.1590/0034-7612146562.

LEÓN, F. R. Is experience in the public sector associated with Big Five personality aspects? Liberabit, v. 23, n. 1, p. 103-109, 2017. DOI: https://doi.org/10.24265/liberabit.2017.v23n1.07.

MARCONI, N. Uma breve comparação entre os mercados de trabalho do setor público e privado. Revista do Serviço Público, v. 48, n. 1, p. 126-146, 2014. DOI: https://doi.org/10.21874/rsp.v48i1.380.

MARQUES, A. L.; BORGES, R.; REIS, I. C. Mudança organizacional e satisfação no trabalho: um estudo com servidores públicos do estado de Minas Gerais. Revista de Administração 
Pública, v. 50, n. 1, p. 41-58, 2016. DOI: https://doi.org/10.1590/0034-7612131034 .

MARQUEZE, E. C.; MORENO, C. R. C. Satisfação no trabalho - uma breve revisão. Revista Brasileira de Saúde Ocupacional, v. 30, n. 112, p. 69-79, 2005. DOI: https://doi.org/10.1590/\$0303-76572005000200007.

MATTOS, C. B. M.; SCHLINDWEIN, V. L. D. C. "Excelência e produtividade": novos imperativos de gestão no serviço público. Psicologia \& Sociedade, v. 27, n. 2, p. 322-331, 2015. DOI: https://doi.org/10.1590/1807-03102015v27n2p322.

PAVOT, W.; DIENER, E. The satisfaction with life scale and the emerging construct of life satisfaction. The Journal of Positive Psychology, v. 3, n. 2, p. 137-152, 2008. DOI: https://doi.org/10.1080/17439760701756946

PERRY, J. L.; HONDEGHEM, A.; WISE, L. R. Revisiting the motivational bases of public service: Twenty years of research and an agenda for the future. Public Administration Review, v. 70, n. 5, p. 681-690, 2010. DOI: https://doi.org/10.1111/j.1540-6210.2010.02196.x.

PERRY, J. L.; WISE, L. R. The motivational bases of public service. Public Administration Review, p. 367-373, 1990.

PINHO, A. P. M.; OLIVEIRA, E. R. S.; SILVA, C. R. M. Comprometimento organizacional no setor público: Um olhar sobre três décadas de produção científica brasileira (1989-2019).

Revista do Serviço Público, v. 71, n. 3, p. 504-539, 2020. DOI:

https://doi.org/10.21874/rsp.v71i3.3507.

RIBEIRO, M. C. C.; OLIVEIRA, E. S. Motivação no setor público: Elemento fundamental para a qualidade da administração pública da secretaria municipal de saúde de Itaperuna/RJ.

Revista Transformar, v. 8, n. 8, p. 264-282, 2016.

RINGLE, C. M.; SILVA, D.; BIDO, D. S. Modelagem de equações estruturais com utilização do SmartPLS. Revista Brasileira de Marketing, v. 13, n. 2, p. 56-73, 2014. DOl: https://doi.org/10.5585/remark.v13i2.2717.

ROELEN, C. A. M.; KOOPMANS, P. C.; NOTENBOMER, A.; GROOTHOFF, J. W. Job satisfaction and sickness absence: A questionnaire survey. Occupational Medicine, v. 58, n. 8, p. 567571, 2008. DOI: https://doi.org/10.1093/occmed/kqn113.

SCHAUFELI, W. B.; BAKKER, A. B.; SALANOVA, M. The measurement of work engagement with a short questionnaire: A cross-national study. Educational and Psychological

Measurement, v. 66, n. 4, p. 701-716, 2006. DOI:

https://doi.org/10.1177/0013164405282471.

SECCHI, L. Modelos organizacionais e reformas da administração pública. Revista de Administração Pública, v. 43, n. 2, p. 347-69, 2009. DOI: https://doi.org/10.1590/S003476122009000200004.

SIQUEIRA, M. V. S.; MENDES, A. M. Gestão de pessoas no setor público e a reprodução do discurso do setor privado. Revista do Serviço Público, v. 60, n. 3, p. 241-250, 2014. DOI: 
Abertura à mudança e engajamento no trabalho como antecedentes da satisfação do servidor público

https://doi.org/10.21874/rsp.v60i3.25.

SIQUEIRA, M. M. M.; PADOVAM, V. A. R. Bases teóricas de bem-estar subjetivo, bem-estar psicológico e bem-estar no trabalho. Psicologia: Teoria e Pesquisa, v. 24, n. 2, p. 201-209, 2008. DOI: https://doi.org/10.1590/S0102-37722008000200010.

SOUZA, A. C.; ALEXANDRE, N. M. C.; GUIRARDELLO, E. B. Propriedades psicométricas na avaliação de instrumentos: Avaliação da confiabilidade e da validade. Epidemiologia e Serviços de Saúde, v. 26, p. 649-659, 2017. DOI: https://doi.org/10.5123/S167949742017000300022.

SOUZA, S. A. D.; MOULIN, M. G. B. Serviço público: Significados e sentidos de um trabalho em mutação. Cadernos de Psicologia Social do Trabalho, v. 17, n. 1, 49-65, 2014. DOI: https://doi.org/10.11606/issn.1981-0490.v17i1p49-65.

TINTI, J. A.; VENELLI-COSTA, L.; VIEIRA, A. M.; CAPPELLOZZA, A. The impact of human resources policies and practices on organizational citizenship behaviors. Brazilian Business Review, v. 14, n. 6, p. 636-653, 2017. DOI: https://doi.org/10.15728/bbr.2017.14.6.6.

VASCONCELLOS, S. J. L.; HUTZ, C. S. Construção e validação de uma escala de abertura à experiência. Avaliação Psicológica, v. 7, n. 2, p. 135-141, 2008.

VIGODA-GADOT, E.; ELDOR, L.; SCHOHAT, L. M. Engage them to public service: Conceptualization and empirical examination of employee engagement in public administration. The American Review of Public Administration, v. 43, n. 5, p. 518-538, 2013. DOI: https://doi.org/10.1177/0275074012450943.

WITTMER, D. Serving the people or serving for pay: Reward preferences among government, hybrid sector, and business managers. Public Productivity \& Management Review, v.14, n. 4, p. 369-383, 1991. DOI: https://doi.org/10.2307/3380953.

WOOD, J.; OH, J.; PARK, J.; KIM, W. The relationship between work engagement and worklife balance in organizations: A review of the empirical research. Human Resource Development Review, v. 19, n. 3, p. 240-262, 2020. DOI: https://doi.org/10.1177/1534484320917560

WOYCIEKOSKI, C.; STENERT, F.; HUTZ, C. S. Determinantes do bem-estar subjetivo. Psico, v. 43, n. 3, p. 1, 2012. 